Machine learning mortality prediction at start of chemotherapy

\title{
A machine learning approach to predicting short-term mortality risk in patients starting chemotherapy
}

Aymen A. Elfiky, MD, MPH, MSc, MBA ${ }^{1,2,3}$

Maximilian J. Pany, BA ${ }^{2,3}$

Ravi B. Parikh, MD, MPP ${ }^{2,3}$

Ziad Obermeyer, MD, MPhil ${ }^{2,3,4}$

1. Dana-Farber Cancer Institute, Boston, MA

2. Harvard Medical School, Boston, MA

3. Brigham and Women's Hospital, Boston, MA

4. Ariadne Labs, Brigham and Women's Hospital and Harvard School of Public Health, Boston, MA

Correspondence to:

Ziad Obermeyer, MD, MPhil

Neville House, 75 Francis St

Boston, MA 02115

Email: zobermeyer@bwh.harvard.edu

Phone: 617-525-3133

Word Count: 2999 
Machine learning mortality prediction at start of chemotherapy

\begin{abstract}
Background: Cancer patients who die soon after starting chemotherapy incur costs of treatment without benefits. Accurately predicting mortality risk from chemotherapy is important, but few patient data-driven tools exist. We sought to create and validate a machine learning model predicting mortality for patients starting new chemotherapy.
\end{abstract}

Methods: We obtained electronic health records for patients treated at a large cancer center (26,946 patients; 51,774 new regimens) over 2004-14, linked to Social Security data for date of death. The model was derived using 2004-11 data, and performance measured on non-overlapping 2012-14 data.

Findings: 30-day mortality from chemotherapy start was $2.1 \%$. Common cancers included breast $(21.1 \%)$, colorectal $(19.3 \%)$, and lung (18.0\%). Model predictions were accurate for all patients (AUC 0.94). Predictions for patients starting palliative chemotherapy (46.6\% of regimens), for whom prognosis is particularly important, remained highly accurate (AUC 0.92). To illustrate model discrimination, we ranked patients initiating palliative chemotherapy by model-predicted mortality risk, and calculated observed mortality by risk decile. 30-day mortality in the highest-risk decile was 22.6\%; in the lowest-risk decile, no patients died. Predictions remained accurate across all primary cancers, stages, and chemotherapies-even for clinical trial regimens that first appeared in years after the model was trained (AUC 0.94). The model also performed well for prediction of 180-day mortality (AUC 0.87 ; mortality $74.8 \%$ in the highest risk decile vs. $0.2 \%$ in the lowest). Predictions were more accurate than data from randomized trials of individual chemotherapies, or SEER estimates.

Interpretation: A machine learning algorithm accurately predicted short-term mortality in patients starting chemotherapy using EHR data. Further research is necessary to determine generalizability and the feasibility of applying this algorithm in clinical settings. 
Machine learning mortality prediction at start of chemotherapy

\section{INTRODUCTION}

Chemotherapy lowers the risk of cancer recurrence in early-stage cancers, and can improve survival and symptoms in later stage disease. Balancing these benefits against chemotherapy's considerable risks is challenging. There is growing evidence that chemotherapy is started too often, too late in the cancer disease trajectory, ${ }^{1-4}$ and many patients die soon after initiating treatment. These patients experience burdensome symptoms and financial costs, without many of the potential benefits of chemotherapy. ${ }^{5}$ National organizations now track the fraction of patients who die within two weeks of receiving chemotherapy as a marker of poor quality of care, ${ }^{6,7}$ and this number has been rising rapidly. 1,8

A key factor underlying these trends is the difficulty of accurately predicting the risk of serious adverse events, especially death, when initiating chemotherapy. Side effects of chemotherapy are variable, and the influence of comorbidities is complex, all making the risk calculus challenging. ${ }^{9-12,13}$ Cognitive biases also lead to underestimation of risk of death, ${ }^{14-15}$ particularly in patients with metastatic cancer ${ }^{16,17}$ who often believe that their disease is curable. ${ }^{18,19}$ Physicians themselves are notoriously bad at estimating prognosis in patients with cancer, ${ }^{20,21}$ and overly optimistic estimates can influence patients' chemotherapy decisions. ${ }^{26-31}$

Currently, doctors may use randomized trial data to estimate mortality for individual regimens, or online tools based on Surveillance, Epidemiology, and End Results (SEER) data to obtain mortality risk by age, sex, and primary cancer. ${ }^{14,28}$ While informative, these tools provide mortality estimates for broad populations of patients, and their relevance to individual decisions is unclear. Individualized decision support tools do exist, ${ }^{29}$ but require a substantial investment of time and resources to collect and enter data not readily available in existing records. There is considerable enthusiasm for the role of advanced algorithms to improve prediction, by drawing on the rich data stored in electronic health records (EHRs) ${ }^{30}$ However, there is little evidence that such algorithms can provide meaningful inputs to clinical decision making, in cancer or elsewhere.

Here we develop and validate a machine learning algorithm to predict near-term mortality risk in patients starting new chemotherapy regimens. New chemotherapy is a critical event in the cancer disease trajectory, and can serve as a 'pause point' to weigh difficult questions. Objective predictions of short-term mortality at this time could be useful to doctors and patients in several ways. First and foremost, estimated likelihood of serious adverse events is an important input to discussions of risks and benefits of treatments, particularly for patients undergoing palliative chemotherapy. ${ }^{31-34}$ Accurate forecasts could also help guide important decisions for patients around family and financial arrangements. Finally, patients at high mortality risk could be prompted to complete advance care planning processes or offered palliative care consultation.

\section{METHODS}

\section{Study Population}


Machine learning mortality prediction at start of chemotherapy

We obtained EHR data for all cancer patients receiving chemotherapy at the DanaFarber/Brigham and Women's Cancer Center (DF/BWCC) from 2004-2014. We determined date of death by linking to the Social Security Administration's Death Master File. We classified patients by primary cancer and presence of distant-stage disease, determined using registry data (for patients diagnosed at DF/BWCC) and International Classification of Diseases (ICD) codes for metastases (for patients not diagnosed at $\mathrm{DF} / \mathrm{BWCC}$ or who did not have registry data; and to identify progression to distant-stage disease in those previously diagnosed at DF/BWCC). ${ }^{35}$ While diagnosis codes have limitations for determination of cancer stage, they are generally believed to reliably identify presence or absence of distant-stage disease. ${ }^{36}$ The institutional review boards of Dana-Farber Cancer Institute and Partners HealthCare approved this study and granted a waiver of informed consent from study participants.

\section{Statistical Analysis}

Dataset: Our primary outcome was death within 30 days of starting new systemic chemotherapy regimens. Secondary outcomes were 30-day mortality in pre-specified subgroups of interest (described below) as well as overall 180-day mortality. We constructed our dataset at the patient-chemotherapy regimen level, such that each observation was a new regimen.

Model performance: Machine learning models have the potential to 'overfit', or produce overly optimistic estimates of model performance based on spurious correlations in development data. We thus report results only in an independent validation set, which played no role in model development; as such, overfitting would only lead to poorer model performance in the validation set. Specifically, we used data from 2004-2011 for model derivation, and data from 2012-2014 for model validation. Importantly, while our dataset was at the patient-chemotherapy regimen level, we randomly assigned patientsnot observations - to the derivation or validation sets, since observations describing different chemotherapy regimens in the same patient were not independent. As such, no patient appeared in both sets.

We report area under the receiver operating characteristic curve (AUC) ${ }^{37}$ with $95 \%$ confidence intervals, ${ }^{38}$ overall and in subgroups of interest, notably age, sex, race, distant-stage disease, individual primary cancers, chemotherapy lines and regimens, and chemotherapy intent (palliative vs. curative, identified by the treating physician, via an EHR flag). To benchmark against existing prognostic models, we obtained one-year mortality estimates from large randomized trials of specific chemotherapies, and from the Surveillance, Epidemiology, and End Results (SEER) program.

Predictors: To transform raw EHR data into variables usable in a prediction model, we first pulled all data from the one-year period ending the day before chemotherapy initiation (we did not drop patients based on absence of data over this period). Raw data were aggregated into 23,641 potential predictors, in the following categories: demographics, prescribed medications, comorbidities and other grouped ${ }^{35}$ ICD-9 diagnoses, procedures, ${ }^{35}$ care utilization, vital signs, laboratory results, and terms derived from physician notes. For each potential predictor, we created two variables, the sum of 
Machine learning mortality prediction at start of chemotherapy

related EHR entries over two time periods: 0-1 months (recent) and 1-12 months (baseline) prior to chemotherapy initiation. This strategy is outlined in more detail elsewhere. ${ }^{39}$ We also included a variable indexing how many lines of chemotherapy the patient had in total prior to the current regimen. No data on the current regimen itself (agent, intent, etc.) were used in the predictive model. We dropped variables missing in over $99 \%$ of the development sample, leaving 5,390 predictors in the model.

Algorithm: We used high-dimensional statistical techniques designed to handle large sets of correlated predictors, specifically gradient boosted trees: a linear combination of decision trees similar to those used to derive many clinical decision rules ${ }^{40}$ (R package: xgboost). ${ }^{41}$ We used 4-fold cross-validation in the development sample to choose model parameters (e.g., number of trees, variables per tree). The model was configured to produce individual-level probabilities of 30-day mortality. More details are available in the Supplemental Methods.

Missing values: Each split of each tree in the model (e.g., a split on sex) had a 'default': the value (e.g., male or female) that occurred more frequently in the training data. Observations with missing values for a given variable were assigned to the default side of the split. This was effectively a split-specific, probabilistic imputation function that allowed us to avoid dropping observations missing data.

Model parameters: Given the complexity of the model, a succinct summary of its parameters was challenging. We attempted to do so by breaking down model predictions into the linear contributions of individual variables, using a decomposition of model predictions on all predictors (in the development sample). We calculated the (linear) sum of squares for each individual variable included in the machine learning model, and interpreted the residual sum of squares as the contribution of non-linear terms and interactions used by the model. Since our model used over 5000 predictors, we chose to report only a small selection, specifically those that most explained model variance, and those identified as predictors of mortality in prior studies. ${ }^{29,42,43}$

\section{RESULTS}

\section{Study Population}

We identified 26,946 patients initiating 51,774 discrete chemotherapy regimens over 2004-2014; 59.4\% had distant-stage disease. Table 1 shows baseline patient characteristics at time of chemotherapy initiation. The most common chemotherapy regimens (derivation and validation sets) were carboplatin-paclitaxel $(n=4042)$, gemcitabine $(n=2185)$, and albumin-bound paclitaxel $(n=1985) ; 3.4 \%$ of the validation set $(n=523)$ received chemotherapy regimens that first appeared in 2012 or later, and thus did not appear in the derivation set, including experimental, non-FDA-approved agents $(2.3 \% ; \mathrm{n}=343)$.

There were several significant differences between the 2004-11 derivation set and the 2012-14 validation set, including age at initiation, race, primary cancer, and prior chemotherapy beyond the first line. Such differences between derivation and validation sets were expected, and indeed intentional: a validation set drawn from later years of data 
Machine learning mortality prediction at start of chemotherapy

was chosen to reflect the constant evolution of cancer epidemiology and treatment. This made the prediction task more difficult, since algorithms trained on past data cannot always perform well in the future, ${ }^{44}$ but accurately represented the difficulties algorithms face in evolving real-world settings.

\section{Model performance}

Among patients in the validation set, overall 30-day mortality was $2.1 \%$, and $3.1 \%$ among those initiating chemotherapy with palliative intent. The model performed accurately for predicting 30-day mortality for all patients, irrespective of chemotherapy intent (AUC: $0.94 ; 95 \%$ CI, 0.93 to 0.95 ). It also performed well when restricting to patients receiving palliative chemotherapy (AUC: 0.92; 95\% CI, 0.91 to 0.94). To illustrate the concrete implications of this, we used model predictions to individually rank patients by 30-day mortality risk, a commonly used way of stratifying risk groups. ${ }^{37} 30$ day mortality in the highest decile of predicted risk was $22.6 \%$, while in the lowest risk decile, not a single patient died.

Figure 1 shows observed survival over the 180 days after palliative chemotherapy initiation by decile of model-predicted 30-day mortality risk. 180-day mortality was higher overall, at $18.4 \%$, but model-predicted 30-day mortality was also an accurate predictor of 180-day mortality (AUC 0.87). 180-day mortality in the highest risk decile was $74.8 \%$, vs. $0.2 \%$ in the lowest risk decile.

Table 2 shows model performance for predicting 30-day mortality in additional patient subgroups of interest. The model performed equally well across many kinds of primary cancers, demographic groups, and chemotherapy regimens. In distant-stage disease (average 30-day mortality: 2.9\%), 30-day mortality in the highest risk decile was $22.7 \%$, vs. $0.0 \%$ in the lowest decile (AUC: $0.94 ; 95 \%$ CI, 0.93 to 0.95 ). Strikingly, predictions were accurate even for experimental new clinical trial regimens first observed over 201214 (AUC: $0.94 ; 95 \%$ CI, 0.88 to 1.0)-i.e., regimens that first appeared in years of data to which the model was not exposed in the training process.

A key question is whether model predictions are accurate enough to be useful across a range of primary cancers, stages of disease, lines of chemotherapy-scenarios whose prognoses vary widely. Table 2 thus also presents measures of overall predictive accuracy for first line (AUC 0.94 for 30-day mortality, 0.87 for 180-day mortality) vs. later lines (AUC 0.94 for 30-day mortality, 0.86 for 180-day mortality) of chemotherapy. eTable 1 presents extended results on accuracy for 30- and 180-day mortality across lung, colorectal, breast, and prostate cancers by stage and line of chemotherapy.

\section{Comparisons to other prognostic estimates}

We compared model performance to two external sources of mortality predictions, focusing on patients with distant-stage disease for whom prognostic estimates are most valuable.

First, we obtained mortality data from four randomized trials of treatments for colorectal adenocarcinoma, non-small cell lung adenocarcinoma, small cell lung carcinoma, and 
Machine learning mortality prediction at start of chemotherapy

squamous cell carcinoma of the head and neck. ${ }^{45-48}$ Figure $2 \mathbf{a}$ shows observed one-year mortality (the only mortality outcome reported consistently) for patients on these regimens in our validation sample, compared to: (1) point estimates of average one-year mortality from relevant clinical trials, and (2) quintiles of estimated mortality risk (30day) from our model. The overall AUC for RCT mean estimates was 0.555 (95\% CI, 0.513 to 0.598$)$, compared to 0.771 ( $95 \% \mathrm{CI}, 0.735$ to 0.808 ) for our individual-level model-based estimates for these same patients.

We also compared our mortality predictions to age-, sex-, race-, and cancer-specific mortality estimates from SEER, restricting to patients with advanced-stage cancers of lung and bronchus, colon and rectum, breast, and prostate to maximize comparability in populations. Figure 2b shows that our estimates were far more accurate (AUC: 0.810; 95\% CI, 0.799 to 0.822 ) than SEER estimates (AUC: $0.600 ; 95 \%$ CI, 0.585 to 0.615 ) for predicting one-year mortality. Further details on construction of RCT and SEER estimates are in the Supplemental Methods and eTable 2, and more detailed comparisons for subgroups are available in eTable 3.

\section{Key predictors}

Table 3 shows the distribution of key predictor variables used in the prediction model across risk deciles, as well as the proportion of model variance explained linearly by each variable. In general, key predictors of mortality identified in the literature were markedly different for patients in the highest vs. lowest model-predicted risk deciles: for example, summed comorbidity score ${ }^{43}$, age $e^{42}$, failure to thrive, heart rate, and certain laboratory data (e.g. C-reactive protein, white blood cell count, alkaline phosphatase). ${ }^{29}$ But importantly, while these differences were striking, no one variable explained more than $2 \%$ of model predictions on its own. Indeed, the majority of variation in the predictions $(86.4 \%)$ was not a linear function of any one predictor, indicating that the tree-based model relied heavily on complex non-linear functional forms and interactions among variables.

\section{DISCUSSION}

A machine learning model based on single-center EHR data accurately estimated individual mortality risk at the time of chemotherapy initiation. The model performed well across a range of cancer types, race, sex, and other demographic variables. Mortality estimates were accurate for palliative as well as curative chemotherapy regimens, for early- and distant-stage patients, and even for patients treated with clinical trial regimens introduced in years after the model was trained. Our model dramatically outperformed estimates from randomized trials and SEER data, both of which are routinely used by clinicians for quantitative risk predictions.

It is notable that this model was able to predict mortality with considerable accuracy despite lacking genetic sequencing data, cancer-specific biomarkers, or indeed any detailed information about cancers beyond EHR data. This underscores the fact that common clinical data elements contained within an EHR-e.g. symptoms, comorbidities, 
Machine learning mortality prediction at start of chemotherapy

prescribed medications, diagnostic tests - contain surprising amounts of signal for predicting key outcomes in cancer patients.

Algorithmic predictions such as ours could be useful at several points along the care continuum. This could include providing accurate predictions of mortality risk to a provider or tumor board at the 'point of decision,' or fostering shared decision making between patient and provider at the 'point of care.' Short-term mortality risk predictions could help clinicians identify patients unlikely to benefit from chemotherapy beyond 30 days, and those who may benefit from early palliative care referral, advance care planning, and prompting to get financial and family affairs in order. For patients receiving systemic chemotherapy, predictable 30-day mortality may even be a useful quality indicator of avoidable treatment-associated harm. ${ }^{49}$

Importantly, while machine learning algorithms require significant computing infrastructure to construct, once derived, they can be applied using only the computing power available on a personal computer or smartphone. This greatly facilitates potential integration into existing clinical systems. While our algorithm was developed using a single institution's data, its data inputs are representative of what is generally available in structured format in EHRs, including ICD and procedure codes, medications, etc. Thus, there are no technical barriers to implementing this or similar algorithms in any organization's clinical data to independently validate predictive power out of sample. To this end, code for our algorithm will be made publicly available (at http://labsysmed.org/wp-content/uploads/2017/02/ChemoMortalityAnalysis.rtf).

This study has several limitations. Our model was built on data from patients treated with chemotherapy, meaning that it answers the question: what is the mortality risk of a a patient starting chemotherapy today? This can be highly useful, since prognostic information informs many important decisions for patients and doctors at a critical point in the disease trajectory. But it also has several important caveats. First, predictions are unlikely to be accurate for untreated patients, meaning the model cannot answer the related question: what is the effect of chemotherapy on mortality risk? Second, our treated sample reflects the particular decisions around chemotherapy made by doctors and patients in our training dataset. Patients who could or would have started chemotherapy, but for some reason did not, would not be included, which can bias the sample. But-for better or worse - the direction of this bias is predictable: prevailing treatment decisions are generally aggressive. In our sample, $62.4 \%$ of patients with distant-stage disease received chemotherapy, and evidence suggests that physicians in a wide range of settings overestimate survival, and overuse chemotherapy. Thus, to the extent that there is bias in our dataset, it leads to the inclusion-not exclusion-of marginal patients, who otherwise might not have received chemotherapy. As a result, we believe this bias did not substantially distort validity. If such an algorithm were deployed in a real-world setting, periodic re-training of the model (e.g., each year or quarter) would ensure that model predictions reflected contemporaneous chemotherapy decision-making. This would address changing selection into treatment over time, and update the model to reflect broader changes in patient populations and chemotherapy technology. 
Machine learning mortality prediction at start of chemotherapy

While we took pains to quantify predictive accuracy in an independent, recent validation set, the only way to truly validate such a model is prospectively. A model trained on pre2012 data may lose accuracy as novel tumor diagnostics and therapies come online, although the accuracy of predictions for patients starting novel chemotherapies was encouraging in this regard. In addition, this is a single-institution study. Further validation is required using cohorts from different institutions. EHR data contain a multitude of biases introduced by physician behavior, institutional idiosyncrasies, and software platforms, among other limitations. These can significantly affect its adaptability and relevance to different care settings.

In conclusion, our machine learning model accurately predicted mortality risk in patients at the time of chemotherapy initiation. While we are optimistic that accurate prognostic tools such as this could help to promote value-driven oncology care, the ideal next step would be a randomized trial of algorithmic estimates at the point of care. To be useful, predictive models must improve decision-making in the real world. Thus rigorous evaluation of predictions' impact on outcomes is the gold standard test-but one that is often neglected in the literature, which focuses primarily on measuring predictive accuracy rather than real outcomes. 
Machine learning mortality prediction at start of chemotherapy

\section{REFERENCES}

1. Emanuel EJ, Young-Xu Y, Levinsky NG, Gazelle G, Saynina O, Ash AS.

Chemotherapy use among Medicare beneficiaries at the end of life. Ann Intern Med 2003;138(8):639-43.

2. Earle CC, Neville BA, Landrum MB, Ayanian JZ, Block SD, Weeks JC. Trends in the Aggressiveness of Cancer Care Near the End of Life. J Clin Oncol 2004;22(2):315-21.

3. Earle CC, Landrum MB, Souza JM, Neville BA, Weeks JC, Ayanian JZ. Aggressiveness of Cancer Care Near the End of Life: Is It a Quality-of-Care Issue? J Clin Oncol 2008;26(23):3860-6.

4. Saito AM, Landrum MB, Neville BA, Ayanian JZ, Earle CC. The effect on survival of continuing chemotherapy to near death. BMC Palliat Care 2011;10:14.

5. Prigerson HG, Bao Y, Shah MA, et al. Chemotherapy Use, Performance Status, and Quality of Life at the End of Life. JAMA Oncol 2015;1(6):778-84.

6. Schnipper LE, Smith TJ, Raghavan D, et al. American Society of Clinical Oncology identifies five key opportunities to improve care and reduce costs: the top five list for oncology. J Clin Oncol Off J Am Soc Clin Oncol 2012;30(14):1715-24.

7. National Quality Forum. Cancer Measures [Internet]. Washington (DC): 2012. Available from: https://www.qualityforum.org/News_And_Resources/Endorsement_Summaries/Can cer_Measures_Endorsement_Summary.aspx

8. Greer JA, Pirl WF, Jackson VA, et al. Effect of early palliative care on chemotherapy use and end-of-life care in patients with metastatic non-small-cell lung cancer. J Clin Oncol Off J Am Soc Clin Oncol 2012;30(4):394-400.

9. Satariano WA, Ragland DR. The effect of comorbidity on 3-year survival of women with primary breast cancer. Ann Intern Med 1994;120(2):104-10.

10. Hall WH, Jani AB, Ryu JK, Narayan S, Vijayakumar S. The impact of age and comorbidity on survival outcomes and treatment patterns in prostate cancer. Prostate Cancer Prostatic Dis 2005;8(1):22-30.

11. Lee L, Cheung WY, Atkinson E, Krzyzanowska MK. Impact of Comorbidity on Chemotherapy Use and Outcomes in Solid Tumors: A Systematic Review. J Clin Oncol 2011;29(1):106-17.

12. van Gestel YRBM, Lemmens VEPP, de Hingh IHJT, et al. Influence of comorbidity and age on 1-, 2-, and 3-month postoperative mortality rates in gastrointestinal cancer patients. Ann Surg Oncol 2013;20(2):371-80. 
Machine learning mortality prediction at start of chemotherapy

13. Sarfati D, Koczwara B, Jackson C. The impact of comorbidity on cancer and its treatment. CA Cancer J Clin 2016;66(4):337-50.

14. Glas NA de, van de Water W, Engelhardt EG, et al. Validity of Adjuvant! Online program in older patients with breast cancer: a population-based study. Lancet Oncol 2014;15(7):722-9.

15. Hoffmann TC, Mar CD. Clinicians' Expectations of the Benefits and Harms of Treatments, Screening, and Tests: A Systematic Review. JAMA Intern Med [Internet] 2017 [cited 2017 Jan 19];Available from: http://jamanetwork.com/journals/jamainternalmedicine/fullarticle/2596010

16. Weeks JC, Cook EF, O'Day SJ, et al. Relationship between cancer patients' predictions of prognosis and their treatment preferences. JAMA 1998;279(21):1709-14.

17. Rose JH, O'Toole EE, Dawson NV, et al. Perspectives, Preferences, Care Practices, and Outcomes Among Older and Middle-Aged Patients With Late-Stage Cancer. J Clin Oncol 2004;22(24):4907-17.

18. Weeks JC, Catalano PJ, Cronin A, et al. Patients' expectations about effects of chemotherapy for advanced cancer. N Engl J Med 2012;367(17):1616-25.

19. Temel JS, Greer JA, Admane S, et al. Longitudinal perceptions of prognosis and goals of therapy in patients with metastatic non-small-cell lung cancer: results of a randomized study of early palliative care. J Clin Oncol Off J Am Soc Clin Oncol 2011;29(17):2319-26.

20. Glare P, Virik K, Jones M, et al. A systematic review of physicians' survival predictions in terminally ill cancer patients. BMJ 2003;327(7408):195.

21. Stone PC, Lund S. Predicting prognosis in patients with advanced cancer. Ann Oncol 2007;18(6):971-6.

22. Brundage MD, Davidson JR, Mackillop WJ. Trading treatment toxicity for survival in locally advanced non-small cell lung cancer. J Clin Oncol 1997;15(1):330-40.

23. Silvestri G, Pritchard R, Welch HG. Preferences for chemotherapy in patients with advanced non-small cell lung cancer: descriptive study based on scripted interviews. BMJ 1998;317(7161):771-5.

24. Hirose T, Yamaoka T, Ohnishi T, et al. Patient willingness to undergo chemotherapy and thoracic radiotherapy for locally advanced non-small cell lung cancer. Psychooncology 2009;18(5):483-9.

25. Keating NL, Landrum MB, Rogers SO, et al. Physician factors associated with discussions about end-of-life care. Cancer 2010;116(4):998-1006. 
Machine learning mortality prediction at start of chemotherapy

26. Keating NL, Beth Landrum M, Arora NK, et al. Cancer patients' roles in treatment decisions: do characteristics of the decision influence roles? J Clin Oncol Off J Am Soc Clin Oncol 2010;28(28):4364-70.

27. Liu P-H, Landrum MB, Weeks JC, et al. Physicians' propensity to discuss prognosis is associated with patients' awareness of prognosis for metastatic cancers. J Palliat Med 2014;17(6):673-82.

28. Statistical Summaries - SEER Cancer Statistics [Internet]. [cited 2017 Jan 19];Available from: https://seer.cancer.gov/statistics/summaries.html

29. Gwilliam B, Keeley V, Todd C, et al. Development of prognosis in palliative care study (PiPS) predictor models to improve prognostication in advanced cancer: prospective cohort study. BMJ 2011;343:d4920.

30. Rumball-Smith J, Shekelle PG, Bates DW. Using the Electronic Health Record to Understand and Minimize Overuse. JAMA 2017;317(3):257-8.

31. Tsao M-S, Aviel-Ronen S, Ding K, et al. Prognostic and Predictive Importance of p53 and RAS for Adjuvant Chemotherapy in Non-Small-Cell Lung Cancer. J Clin Oncol 2007;25(33):5240-7.

32. Van Laar RK. Genomic signatures for predicting survival and adjuvant chemotherapy benefit in patients with non-small-cell lung cancer. BMC Med Genomics 2012;5:30.

33. Dalerba P, Sahoo D, Paik S, et al. CDX2 as a Prognostic Biomarker in Stage II and Stage III Colon Cancer. N Engl J Med 2016;374(3):211-22.

34. Kratz JR, He J, Van Den Eeden SK, et al. A practical molecular assay to predict survival in resected non-squamous, non-small-cell lung cancer: development and international validation studies. Lancet Lond Engl 2012;379(9818):823-32.

35. Healthcare Cost and Utilization Project (HCUP). Clinical Classifications Software for Services and Procedures [Internet]. [cited 2017 Jan 19];Available from: https://www.hcup-us.ahrq.gov/toolssoftware/ccs_svcsproc/ccssvcproc.jsp

36. Cooper GS, Yuan Z, Stange KC, Amini SB, Dennis LK, Rimm AA. The Utility of Medicare Claims Data for Measuring Cancer Stage. Med Care 1999;37(7):706-11.

37. Meurer WJ, Toles J. Logistic regression diagnostics: Understanding how well a model predicts outcomes. JAMA 2017;317(10):1068-9.

38. DeLong ER, DeLong DM, Clarke-Pearson DL. Comparing the areas under two or more correlated receiver operating characteristic curves: a nonparametric approach. Biometrics 1988;44(3):837-45. 
Machine learning mortality prediction at start of chemotherapy

39. Makar M, Ghassemi M, Cutler DM, Obermeyer Z. Short-term mortality prediction for elderly patients using Medicare claims data. Int J Mach Learn Comput 2015;5(3):192-7.

40. Goldman L, Weinberg M, Weisberg M, et al. A computer-derived protocol to aid in the diagnosis of emergency room patients with acute chest pain. N Engl J Med 1982;307(10):588-96.

41. Chen T, He T. xgboost: eXtreme Graident Boosting [Internet]. 2017;Available from: https://cran.r-project.org/web/packages/xgboost/vignettes/xgboost.pdf

42. Shouval R, Labopin M, Bondi O, et al. Prediction of Allogeneic Hematopoietic Stem-Cell Transplantation Mortality 100 Days After Transplantation Using a Machine Learning Algorithm: A European Group for Blood and Marrow Transplantation Acute Leukemia Working Party Retrospective Data Mining Study. J Clin Oncol 2015;33(28):3144-51.

43. Gagne JJ, Glynn RJ, Avorn J, Levin R, Schneeweiss S. A combined comorbidity score predicted mortality in elderly patients better than existing scores. J Clin Epidemiol 2011;64(7):749-59.

44. Moreno-Torres JG, Raeder T, Alaiz-Rodríguez R, Chawla NV, Herrera F. A unifying view on dataset shift in classification. Pattern Recognit 2012;45(1):521-30.

45. Saltz LB, Clarke S, Díaz-Rubio E, et al. Bevacizumab in Combination With Oxaliplatin-Based Chemotherapy As First-Line Therapy in Metastatic Colorectal Cancer: A Randomized Phase III Study. J Clin Oncol 2008;26(12):2013-9.

46. Zukin M, Barrios $\mathrm{CH}$, Pereira JR, et al. Randomized phase III trial of single-agent pemetrexed versus carboplatin and pemetrexed in patients with advanced non-smallcell lung cancer and Eastern Cooperative Oncology Group performance status of 2. J Clin Oncol Off J Am Soc Clin Oncol 2013;31(23):2849-53.

47. Noda K, Nishiwaki Y, Kawahara M, et al. Irinotecan plus Cisplatin Compared with Etoposide plus Cisplatin for Extensive Small-Cell Lung Cancer. N Engl J Med 2002;346(2):85-91.

48. Clark JI, Hofmeister C, Choudhury A, et al. Phase II evaluation of paclitaxel in combination with carboplatin in advanced head and neck carcinoma. Cancer 2001;92(9):2334-40.

49. Wallington M, Saxon EB, Bomb M, et al. 30-day mortality after systemic anticancer treatment for breast and lung cancer in England: a population-based, observational study. Lancet Oncol 2016;17(9):1203-16. 
bioRxiv preprint doi: https://doi.org/10.1101/204081; this version posted October 19,2017 . The copyright holder for this preprint (which was not certified by peer review) is the author/funder, who has granted bioRxiv a license to display the preprint in perpetuity. It is made available under aCC-BY-NC-ND 4.0 International license.

Machine learning mortality prediction at start of chemotherapy 
bioRxiv preprint doi: https://doi.org/10.1101/204081; this version posted October 19,2017 . The copyright holder for this preprint (which was not certified by peer review) is the author/funder, who has granted bioRxiv a license to display the preprint in perpetuity. It is made available under aCC-BY-NC-ND 4.0 International license.

Machine learning mortality prediction at start of chemotherapy

\section{FIGURES and TABLES}

Figure 1. Observed survival over the 180 days from the initiation of palliative chemotherapy, by decile of model-predicted mortality risk. $q 1$ denotes the highest predicted risk decile, $q 2$ the second highest, $q 9$ the second lowest, and $q 10$ the lowest. Overall denotes overall mean survival in all patients, irrespective of model-predicted risk.

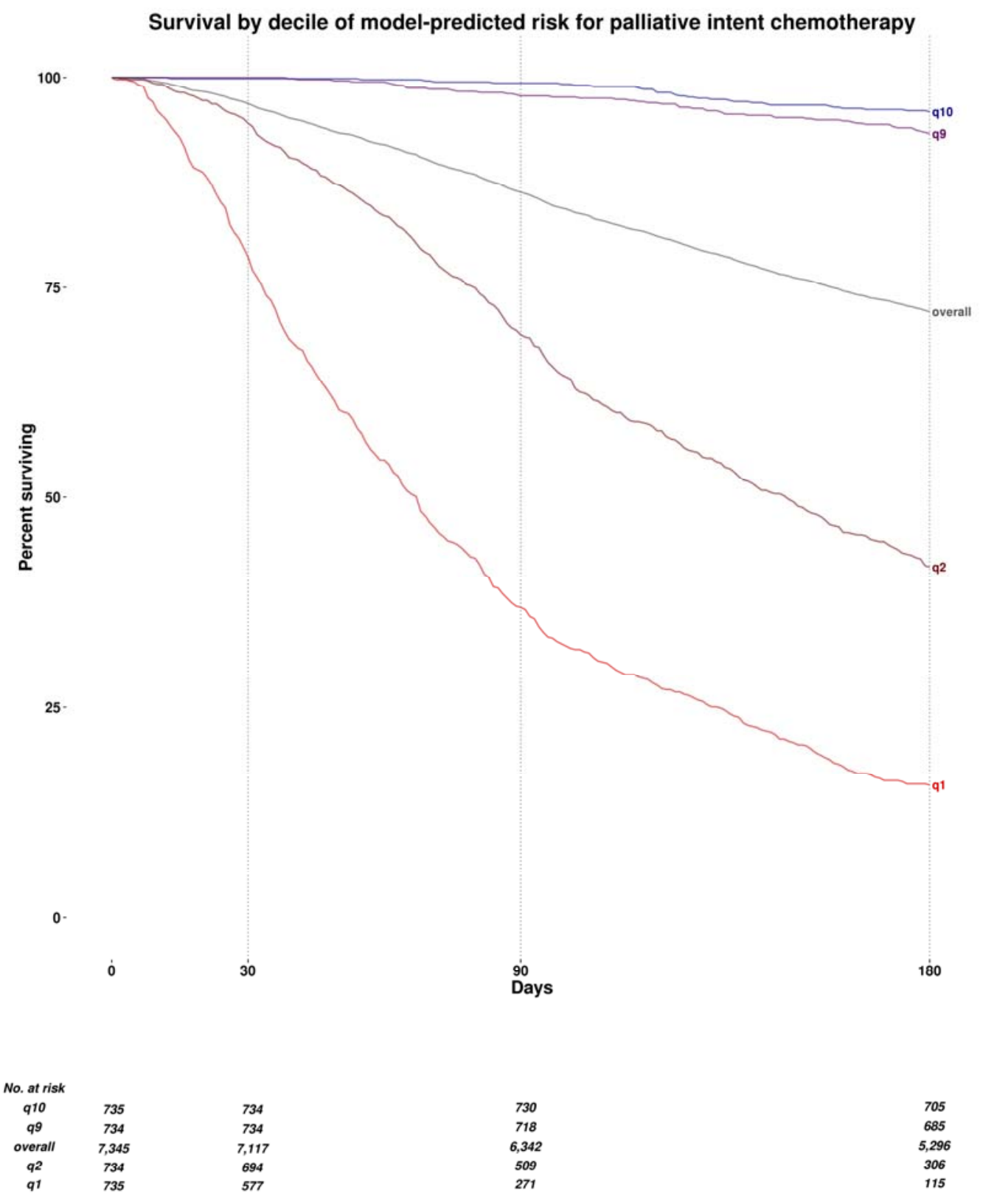


Machine learning mortality prediction at start of chemotherapy

Figure 2. Observed one-year mortality (y-axis) from start of chemotherapy for patients with specific combinations of distant-stage cancers and chemotherapies, shown against mortality predictions from three sources (x-axis). The $45^{\circ}$ dotted line denotes equivalence of observed and estimated mortality.

Orange lines, with shaded $95 \%$ confidence intervals, show mean observed one-year mortality against quintiles of estimated one-year mortality based on our model-predicted 30-day mortality risk. Blue lines, with shaded $95 \%$ confidence intervals, show observed one-year mortality against predictions from two other sources. In Panel (a), we show mean one-year mortality and 95\% CI (blue dots and bars) from individual randomized trials. Of note, trial data provide only single point estimates for mortality, based on average mortality in the trial, leading to one point estimate on the graphs. In Panel (b), we show mean observed one-year mortality against quantiles of estimated one-year mortality risk from the National Cancer Institute's Surveillance, Epidemiology, and End Results (SEER) program, estimated using cancer type, age, sex, and race.

Histograms show the distribution of individual estimates of mortality risk, colored by source of estimate: orange for our model predictions, blue for RCT estimates (Panel a) and SEER estimates (Panel b).

a
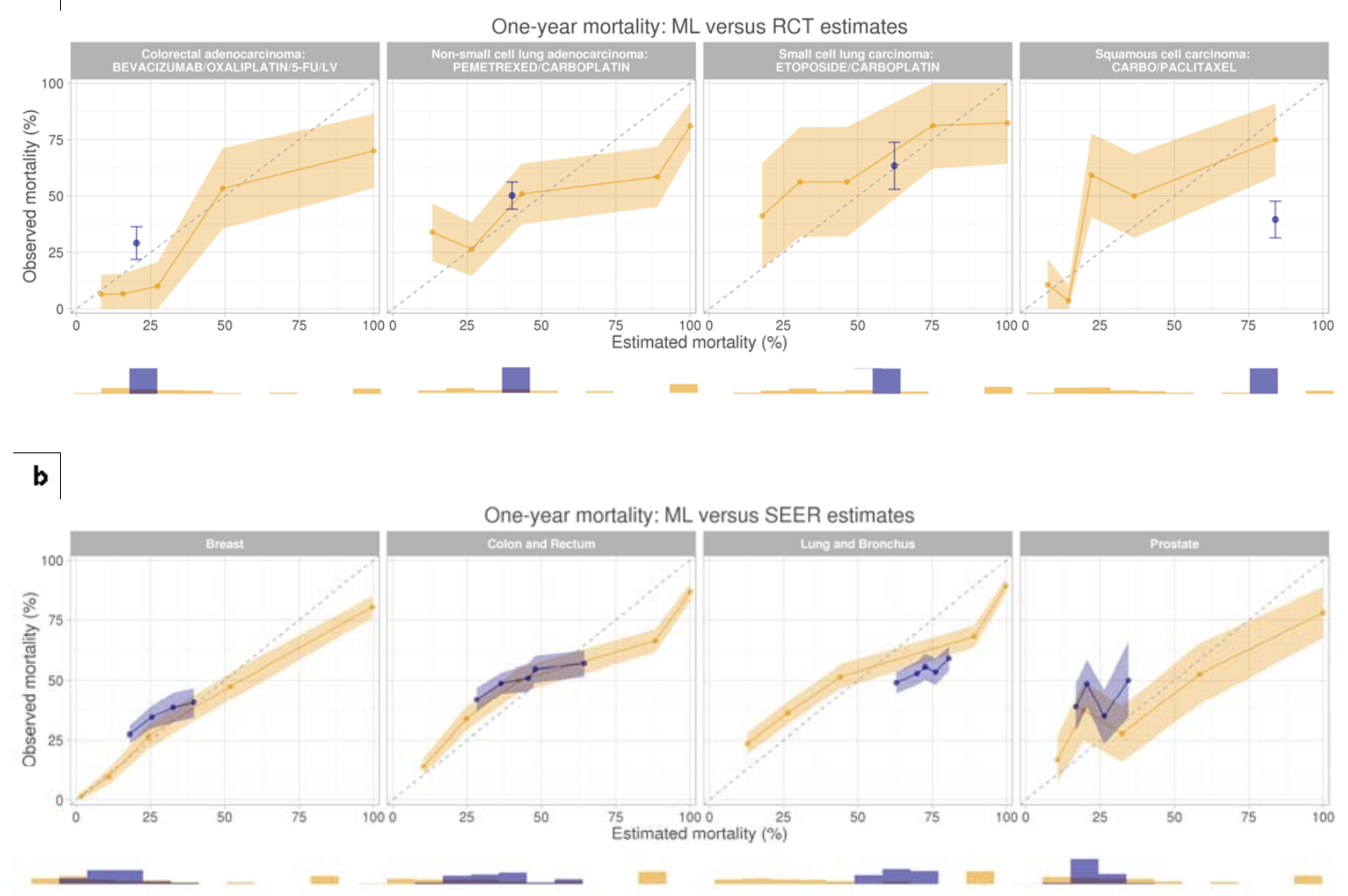
Machine learning mortality prediction at start of chemotherapy

Table 1. Baseline patient characteristics of model derivation and validation sets.

\section{Sample}

\begin{tabular}{|c|c|c|c|}
\hline Variable & Derivation & Validation & Difference \\
\hline Patients, $\mathrm{n}$ & 17,832 & 9,114 & 8,718 \\
\hline Chemo regimens, $\mathrm{n}$ & 36,007 & 15,767 & 20,240 \\
\hline Age, mean $(95 \% \mathrm{Cl})$ & 58.7 (58.5 to 58.9$)$ & $60.7(60.5$ to 61$)$ & $-2.1(-2.4$ to -1.7$)$ \\
\hline Female, \% (95\% Cl) & $61.1(60.4$ to 61.9$)$ & 60.7 (59.7 to 61.7$)$ & $0.5(-0.7$ to 1.7$)$ \\
\hline White, \% (95\% Cl) & $86.9(86.4$ to 87.4$)$ & 88.3 (87.7 to 89$)$ & $-1.5(-2.3$ to -0.7$)$ \\
\hline IP visit, \% (95\% Cl) & 43.9 (43.2 to 44.6$)$ & 38 (37 to 38.9$)$ & 6 (4.7 to 7.2$)$ \\
\hline Gagne score, median (IQR) & $2(1$ to 6$)$ & $1(1$ to 6$)$ & $-1(0 \text { to } 0)^{a}$ \\
\hline \multicolumn{4}{|l|}{ Cancer type, \% (95\% Cl) } \\
\hline Breast & 23.6 (23 to 24.3 ) & 21.1 (20.2 to 21.9$)$ & 2.5 (1.5 to 3.6$)$ \\
\hline Colon and Rectum & 17.6 (17.1 to 18.2$)$ & 19.3 (18.5 to 20.2$)$ & $-1.7(-2.7$ to -0.7$)$ \\
\hline Lung and Bronchus & 17.7 (17.2 to 18.3$)$ & 18 (17.2 to 18.8$)$ & $-0.3(-1.3$ to 0.7$)$ \\
\hline Hematological & $7.1(6.7$ to 7.5$)$ & 8.4 (7.8 to 8.9$)$ & $-1.3(-2$ to -0.6$)$ \\
\hline Ovary & 6.7 (6.3 to 7$)$ & 7.7 (7.1 to 8.2$)$ & $-1(-1.7$ to -0.3$)$ \\
\hline $\begin{array}{l}\text { Other } \\
\text { Chemo beyond first line, } \\
\%(95 \% \mathrm{Cl}) \\
\text { Intent of chemotherapy \% } \\
(95 \% \mathrm{Cl})^{b}\end{array}$ & $\begin{array}{l}27.8(27.1 \text { to } 28.4) \\
49(48.3 \text { to } 49.7)\end{array}$ & $\begin{array}{l}25.8 \text { (24.9 to } 26.7) \\
42.4(41.4 \text { to } 43.4)\end{array}$ & $\begin{array}{l}2(0.9 \text { to } 3.1) \\
6.6(5.3 \text { to } 7.8)\end{array}$ \\
\hline Curative & 15.7 (15.3 to 16.1$)$ & 26.8 (26.1 to 27.5$)$ & $-11.1(-11.9$ to -10.3$)$ \\
\hline Palliative & 33.8 (33.3 to 34.3$)$ & 46.6 (45.8 to 47.3$)$ & $-12.7(-13.7$ to -11.8$)$ \\
\hline
\end{tabular}


Machine learning mortality prediction at start of chemotherapy

Table 2. Model performance in selected subgroups.

\begin{tabular}{|c|c|c|}
\hline \multirow[b]{2}{*}{ Subgroup } & \multicolumn{2}{|c|}{ AUC $(95 \% \mathrm{Cl})$} \\
\hline & 30-day mortality & 180-day mortality \\
\hline \multicolumn{3}{|l|}{ Intent of chemotherapy } \\
\hline Curative & 0.981 (0.970 to 0.992$)$ & 0.892 (0.872 to 0.912$)$ \\
\hline Palliative & 0.924 (0.910 to 0.939$)$ & $0.827(0.817$ to 0.838$)$ \\
\hline \multicolumn{3}{|l|}{ Stage } \\
\hline Distant stage & 0.938 (0.926 to 0.951$)$ & $0.852(0.842$ to 0.861$)$ \\
\hline Non-distant stage & $0.936(0.916$ to 0.955$)$ & $0.874(0.862$ to 0.887$)$ \\
\hline \multicolumn{3}{|l|}{ Cancer } \\
\hline Breast & $0.970(0.956$ to 0.983$)$ & $0.939(0.928$ to 0.951$)$ \\
\hline Colon and Rectum & 0.924 (0.898 to 0.949$)$ & $0.843(0.827$ to 0.860$)$ \\
\hline Lung and Bronchus & 0.916 (0.884 to 0.949$)$ & 0.820 (0.803 to 0.838$)$ \\
\hline Ovary & 0.956 (0.922 to 0.989$)$ & 0.895 (0.871 to 0.918$)$ \\
\hline Hematological & $0.943(0.902$ to 0.983$)$ & $0.819(0.782$ to 0.856$)$ \\
\hline Head and Neck & $0.970(0.933$ to 1.000$)$ & $0.839(0.798$ to 0.879$)$ \\
\hline Cervix Uteri & 0.955 (0.906 to 1.000$)$ & 0.888 (0.847 to 0.929$)$ \\
\hline Prostate & $0.936(0.849$ to 1.000$)$ & $0.805(0.751$ to 0.858$)$ \\
\hline \multicolumn{3}{|l|}{ Chemotherapy regimen } \\
\hline Carbo/paclitaxel & $0.940(0.859$ to 1.000$)$ & $0.846(0.813$ to 0.880$)$ \\
\hline FOLFOX & $0.952(0.923$ to 0.982$)$ & 0.863 (0.833 to 0.893$)$ \\
\hline Gemcitabine & 0.865 (0.789 to 0.942$)$ & $0.992(0.982$ to 1.000$)$ \\
\hline Pemetrexed/carboplatin & 0.960 (0.939 to 0.981$)$ & 0.807 (0.769 to 0.845$)$ \\
\hline Paclitaxel & $0.989(0.972$ to 1.000$)$ & $0.738(0.686$ to 0.791$)$ \\
\hline Novel clinical trial agents ${ }^{a}$ & $0.942(0.882$ to 1.000$)$ & 0.870 (0.817 to 0.923$)$ \\
\hline \multicolumn{3}{|l|}{ Line of chemotherapy } \\
\hline First line & 0.941 (0.925 to 0.956$)$ & 0.865 (0.854 to 0.875$)$ \\
\hline Subsequent line & 0.938 (0.924 to 0.952$)$ & $0.864(0.854$ to 0.874$)$ \\
\hline \multicolumn{3}{|l|}{$Y_{e a r^{\mathrm{b}}}$} \\
\hline 2012 & $0.951(0.935$ to 0.966$)$ & $0.887(0.875$ to 0.899$)$ \\
\hline 2013 & 0.935 (0.914 to 0.955$)$ & 0.869 (0.857 to 0.882$)$ \\
\hline 2014 & $0.928(0.908$ to 0.947$)$ & $0.837(0.824$ to 0.851$)$ \\
\hline \multicolumn{3}{|l|}{ Age group } \\
\hline $21-40$ & 0.963 (0.939 to 0.988$)$ & 0.901 (0.874 to 0.928$)$ \\
\hline $41-60$ & $0.950(0.935$ to 0.966$)$ & 0.893 (0.883 to 0.903$)$ \\
\hline $61-80$ & $0.936(0.920$ to 0.951$)$ & $0.850(0.839$ to 0.861$)$ \\
\hline $81-100$ & 0.876 (0.806 to 0.947$)$ & 0.803 (0.768 to 0.838$)$ \\
\hline \multicolumn{3}{|l|}{ Gender } \\
\hline Female & $0.948(0.935$ to 0.962$)$ & $0.886(0.877$ to 0.894$)$ \\
\hline Male & 0.927 (0.910 to 0.944$)$ & 0.840 (0.828 to 0.852$)$ \\
\hline \multicolumn{3}{|l|}{ Race } \\
\hline White & $0.940(0.929$ to 0.951$)$ & 0.870 (0.862 to 0.877$)$ \\
\hline Non-white & 0.941 (0.909 to 0.972$)$ & $0.870(0.850$ to 0.891$)$ \\
\hline \multicolumn{3}{|l|}{ Insurance } \\
\hline Private & $0.949(0.937$ to 0.962$)$ & $0.886(0.878$ to 0.895$)$ \\
\hline Medicare & $0.938(0.911$ to 0.965$)$ & 0.854 (0.837 to 0.872$)$ \\
\hline Medicaid & $0.945(0.914$ to 0.976$)$ & $0.824(0.784$ to 0.865$)$ \\
\hline Self-pay & $0.932(0.851$ to 1.000$)$ & 0.821 (0.753 to 0.888$)$ \\
\hline
\end{tabular}

a Subgroup of patients receiving new clinical trial regimens first observed over 2012-14, i.e., years of data to which the model was not exposed in the training process.

${ }^{b}$ Observations in the validation set occurring in $2011(n=717)$ were reassigned to 2012 for the purpose of this table. 
bioRxiv preprint doi: https://doi.org/10.1101/204081: this version posted October 19,2017 . The copyright holder for this preprint (which was not certified by peer review) is the author/funder, who has granted bioRxiv a license to display the preprint in perpetuity. It is made available under aCC-BY-NC-ND 4.0 International license.

Machine learning mortality prediction at start of chemotherapy

Table 3. Selected variables by risk decile and model variance explained.

\begin{tabular}{|c|c|c|c|c|}
\hline \multirow[b]{2}{*}{ Variable } & \multicolumn{3}{|c|}{ Variable mean, by risk decile } & \multirow[b]{2}{*}{$\begin{array}{l}\text { Model } \\
\text { variance } \\
\text { explained }\end{array}$} \\
\hline & Top & Median & Bottom & \\
\hline \multicolumn{5}{|l|}{ Cancer } \\
\hline Brain and other NS & 6.7 & 1.6 & 0.0 & $1.94 \%$ \\
\hline \multicolumn{5}{|l|}{ Demographics } \\
\hline Age & 62.3 & 62.1 & 51.9 & $1.30 \%$ \\
\hline Female & 56.4 & 60.9 & 86.9 & $1.17 \%$ \\
\hline Black & 3.8 & 3.6 & 3.4 & $0.07 \%$ \\
\hline Comorbidity score & 5.14 & 3.44 & 2.01 & $0.03 \%$ \\
\hline Ascites & 0.31 & 0.07 & 0.01 & $0.39 \%$ \\
\hline Mouth disorder & 0.02 & 0.01 & 0.01 & $0.25 \%$ \\
\hline Nausea and vomiting & 0.23 & 0.09 & 0.01 & $0.18 \%$ \\
\hline Lower respiratory disorders & 2.10 & 1.36 & 0.16 & $0.03 \%$ \\
\hline Secondary malignancy & 5.57 & 1.69 & 0.36 & $0.01 \%$ \\
\hline Failure to thrive & 0.05 & 0.01 & 0.00 & $0.01 \%$ \\
\hline Nutritional disorders & 2.53 & 1.63 & 0.54 & $0.00 \%$ \\
\hline Malaise and fatigue & 0.22 & 0.08 & 0.02 & $0.00 \%$ \\
\hline \multicolumn{5}{|l|}{ Medications } \\
\hline Corticosteroids & 0.53 & 0.00 & 0.00 & $0.15 \%$ \\
\hline Opioids & 0.29 & 0.00 & 0.00 & $0.05 \%$ \\
\hline Anxiolytics & 0.60 & 0.24 & 0.18 & $0.02 \%$ \\
\hline Cathartic & 0.54 & 0.00 & 0.00 & $0.00 \%$ \\
\hline \multicolumn{5}{|l|}{ Vital signs $^{a}$} \\
\hline Pulse, max (year) & 106.1 & 95.7 & 87.1 & $0.37 \%$ \\
\hline Weight, max (year) & 79.5 & 80.2 & 76.8 & $0.11 \%$ \\
\hline Weight, standard deviation (year) & 3.1 & 2.1 & 1.3 & $0.06 \%$ \\
\hline Pulse, min (month) & 83.4 & 72.8 & 63.0 & $0.01 \%$ \\
\hline Weight change ${ }^{b}$ & -3.1 & -1.0 & 0.1 & $0.00 \%$ \\
\hline \multicolumn{5}{|l|}{ Labs $^{\text {a }}$} \\
\hline C-reactive protein, max & 93.9 & 65.6 & 2.2 & $0.19 \%$ \\
\hline SGPT, max & 75.9 & 57.3 & 24.3 & $0.07 \%$ \\
\hline SGOT, max & 73.7 & 54.2 & 23.8 & $0.09 \%$ \\
\hline White blood cell count, max & 13.9 & 12.4 & 9.8 & $0.03 \%$ \\
\hline Alkaline phosphatase, $\max$ & 199.5 & 128.7 & 76.5 & $0.02 \%$ \\
\hline Lymphocytes, mean & 1.0 & 1.3 & 1.8 & $0.00 \%$ \\
\hline Platelets, mean & 251.8 & 241.4 & 265.1 & $0.00 \%$ \\
\hline Ejection fraction & 54.4 & 48.0 & 51.9 & $0.01 \%$ \\
\hline \multirow{2}{*}{\multicolumn{4}{|c|}{$\begin{array}{l}\text { Total, linear terms } \\
\text { Total, nonlinear terms and interactions }\end{array}$}} & 13.6 \\
\hline & & & & 86.4 \\
\hline \multicolumn{5}{|c|}{$\begin{array}{l}\text { a "Year" and "month" denote the value of the variable (minimum, maximum, or standard deviation, as noted) } \\
\text { over the } 12 \text { months and } 1 \text { month prior to chemotherapy initiation, respectively } \\
\text { benotes the change in weight from the average value over the } 12 \text { months prior to chemotherapy initiation } \\
\text { to the average value over the } 1 \text { month prior to chemotherapy initiation } \\
\text { "Denotes the value of the variable (minimum, maximum, as noted) over the } 12 \text { months prior to } \\
\text { chemotherapy initiation. }\end{array}$} \\
\hline
\end{tabular}

